\title{
Predicting international students' clinical and academic grades using two language tests (IELTS and C-test): a correlational research study
}

Article

Accepted Version

Daller, M. (2019) Predicting international students' clinical and academic grades using two language tests (IELTS and C-test): a correlational research study. Nurse Education Today, 72. pp. 6-11. ISSN 0260-6917 doi: https://doi.org/10.1016/j.nedt.2018.10.007 Available at https://centaur.reading.ac.uk/80251/

It is advisable to refer to the publisher's version if you intend to cite from the work. See Guidance on citing.

To link to this article DOI: http://dx.doi.org/10.1016/j.nedt.2018.10.007

Publisher: Elsevier

All outputs in CentAUR are protected by Intellectual Property Rights law, including copyright law. Copyright and IPR is retained by the creators or other copyright holders. Terms and conditions for use of this material are defined in the End User Agreement. 


\section{CentAUR}

Central Archive at the University of Reading

Reading's research outputs online 


\title{
NURSE EDUCATION TODAY
}

\section{Predicting international students' clinical and academic grades using two language tests (IELTS and C-test): a correlational research study}

Amanda Müller and Michael Daller

\begin{abstract}
Academic English tests are used to ascertain if international English as a Second Language nursing students have sufficient language skills to commence their nursing degrees, and later, if they have sufficent English for nursing registration. However, an academic English test may not be appropriate for clinical contexts. This study examines the relationship between two types of English test and the performance of forty-nine undergraduate international nursing students in both their first year of theory-centred academic topics and practice-centred clinical topics. An academic English test, called the International English Language Testing System (IELTS) and a general English proficiency/processing speed test using a variation of the cloze-test (C-test) format were administered at the commencement of the students' course of study. At the end of one year, grade percentages were collected. It was found that both the IELTS test and the C-test were significantly correlated to both types of topic, albeit with different patterns. The two English tests were also tested for similarities in the constructs they measured, with a significant overlap found. The implications are to rethink the way English tests are applied to entry in university degrees involving a clinical component and, by extension, to direct universities to rethink how nursing students are supported during their degree. The question is also raised about the practice of using academic English tests for professional nursing registration purposes. The cost benefits of the two testing approaches is also considered, particularly the large differences in monetary outlay and time found between the two tests, given their performance in explaining the variance in grade outcomes.
\end{abstract}

\section{Keywords}

Linguistics; English as a Second Language; Educational Assessment; Nursing Students; Nursing Education

\section{Background}

Entry into a university degree typically requires the student to prove their English proficiency, using either an English language test or providing other forms of evidence. The preferred English tests accepted by most universities are usually the academic versions American Test of English as a Foreign Language (TOEFL) and the Australian/British International English Language Testing System (IELTS). Institutions around the world will usually accept either of these tests (there are other common tests, such the Certificate in Advanced English and Pearson Test of English, which may also be recognised).

The dominant English test in Australia is International English Language Testing System (IELTS), partly because it was created in response to Australian universities increasing their recruitment of international students (Ahern, 2009), and later, as it became Australia's preferred test for migration 
and professional registration (Birrell, 2006). IELTS is designed to assess current "readiness to enter the world of university-level study" (Cambridge ESOL, 2004, p.15). IELTS is similar to other tests such as the online TOEFL because it focuses on the kind of English used in generic academic tasks. These generic academic tasks include writing essays, interpreting graphs, reading informational texts, listening to lectures, talking about oneself (including hobbies and home country), and giving opinions (on aspects of society or preferred activities). For listening and reading, the questions focus on the comprehension of linguistic input with test questions appearing in the format of true/false/not given, multiple choice, gap fill, diagram/table fill, appropriate headings, and so on. The IELTS test has a strong focus on the comprehension of academic texts, so this comprises a separate portion of the final IELTS scoring rubric.

The relationship between IELTS and future academic success varies. Many studies report a weak to moderate positive correlation of around .3 (Kerstjens \& Nery, 2000) for either the whole test or its subtests. Grade correlations are affected by the type of subject studied, undergraduate or postgraduate, homogeneous populations, and the range of IELTS and grade point average (GPA) scores represented in the population (Huong 2001; Dooey, 1999). A serious issue in nearly all the studies was a truncated sample size, where the range of IELTS scores was limited, and which is likely to have resulted in a depressed predictive validity coefficient (Daller \& Phelan, 2013; Huong, 2001), particularly a lack of the lower scores which would have the largest effect on grades. Another related issue is a likely ceiling effect for high scores. To explain, when people with insufficient English cannot interact effectively in an academic environment, their grades will suffer. However, there will be a point when their English skills become good enough that it no longer obstructs communication. When this happens, English should no longer be a factor in determining grades (a parallel example is that we do not expect all native English speakers to get high grades just because they are fluent in English). There are no specific studies setting out to find a ceiling effect of this kind for IELTS, but it has been noted in a number of studies generally looking at IELTS test scores and academic outcomes (Dooey, 1999; Feast, 2002; Floyd, 2015; Kerstjens \& Nery, 2000).

International students struggle with the language component of their studies, despite passing IELTS or completing other pathways to establish their academic and formal English proficiency (Crawford \& Candlin, 2013a; Donnelly, McKiel, \& Hwang, 2009; Starr, 2009; Wang, Andre, \& Greenwood 2014). International students notably struggle in the clinical arena where they have to switch between the medical language of co-workers and the colloquial language of patients. International students report issues with medical terminology (Terwijn, Pearce, \& Rogers-Clark, 2012), speed of communication (Crawford \& Candlin, 2013a), end-of-shift handovers (Abu-Arab \& Parry, 2015), colloquialisms (Blackmann \& Hall, 2009; Pardue \& Haas, 2003), and so on. In fact, a nursing degree has been conceptualised as comprising two parts: academic and clinical skills (Bosher, 2010, p.353). Nursing academic skills are most closely aligned with those found in the social sciences or the natural sciences (Bosher, 2010). However, nursing clinical skills have both shared and unique properties relative to other health sciences. The shared properties arise from team-based healthcare and professional tasks, but the different communicative contexts involved in the round-the-clock team-based care of nursing is quite different to the narrowly defined episodic care provided by many other health professions. The focus of nursing education ranges from the academic learning of issues regarding the psychosocial aspects of nursing, ethics, pharmacology, and pathophysiology to the learning of practical clinical tasks in the laboratory, simulation suites, and external clinical 
placement venues which require spontaneous communication. This spontaneous communication may also include the colloquial language of both patients and the nurses caring for them. Returning to IELTS and its focus on academic tasks, it is clear that the test covers one type of language (i.e. academic) out of at least three possible types (i.e. medical and colloquial) that occur in nursing contexts. In fact, IELTS actively removes problematic language items - such as local colloquialisms and medical jargon - from its test banks (Ingram, 1995).

Given that the clinical component of nursing education requires general linguistic fluency skills, and tests like IELTS are heavily focused on the four skills of listening, speaking, reading, and writing in academic contexts, the question arises whether other ways of testing English might perform better in establishing English proficiency for nursing contexts. One example of a language proficiency test format is the modified cloze test (C-test), currently used as a placement test at a number of German and Dutch educational institutions (e.g. HU Berlin, University of Bielefeld, University of Muenster, and the University of Groningen). The C-test format has been used with many different languages and the latest bibliography contains 528 publications about the C-test format's efficacy (Grotjahn, 2016). This includes non-European languages, such as Arabic, Turkish and Chinese. No disadvantage to speakers from specific language backgrounds has yet emerged. Centred upon vocabulary semi-gap fills, the C-test format is seen by many researchers as a measure of "general language proficiency" (Eckes \& Grotjahn, 2006; Klein-Braley, 1985; Raatz, 1985; Sigott, 2004; Sigott, 2006). This is supported by the fact that C-test scores generally correlate significantly with scores in other language tests, including for oral proficiency (Eckes \& Grotjahn, 2006; Sigott, 2004; Sigott, 2006), despite its greatly reduced focus on comprehension of the subject of the text (i.e. the comprehension component of IELTS tasks).

The C-test format is based on the concept of reduced redundancy (Spolsky, 1971). Natural language contains redundant elements which allow a speaker to restore linguistic elements that have been deleted or are difficult to analyse, e.g. because of noise. Native speakers are better in restoring unintelligible parts of a spoken or written text than foreign language learners. Oller (1976) calls this capacity "expectancy grammar". These concepts have been used to develop test formats but the concepts themselves have not been analysed in great detail. In recent years, eye-tracking methods have been used and the term "predictive processing" has emerged (e.g. Hopp 2015; Hopp, 2016). Thus, rather than focusing on comprehension in the four language skill areas, the C-test format focuses on how quickly the person can deal with redundancies, their processing speed (Wockenfuß \& Raatz, 2014), their knowledge of grammar and syntax, and their general vocabulary knowledge: thus the C-test format is a test of general English proficiency and processing speed. Hull (2015) conceptualises the language of healthcare as being comprised of proficiency, fluency, and command (i.e. vocabulary) of English, and the C-test contains these three elements. It is possible then, given the fast pace of clinical environments and the need to spontaneously receive and produce language in a pressured fast environment, that the C-test format might be a good measure of a person's ability to perform in such an environment. Furthermore, a C-test can easily be tailored to use disciplinespecific materials as its base text, even though this is not typical practice.

\section{Objectives}

This study sought to determine if there is a difference in the relationship between the IELTS (an academic-focused English test) and the C-test (a general test of English proficiency and processing 
speed) with academic topics (classroom-based theoretical topics) and clinical topics (laboratorybased practical topics involving clinical placements in outside venues such as hospitals, aged-care facilities, and community services). Thus, the following research questions were formed:

1. Does an academic English test (IELTS) have a stronger relationship to grade outcomes for academic topics than for clinical topics, given that the test was designed for academic contexts?

2. Does a test of general English proficiency and processing speed (C-test) have a stronger relationship to clinical topics, given the greater requirement for spontaneous spoken communication and broader varieties of English encountered in clinical situations?

\section{Design}

This study used a correlational design. Ethics approval was gained from Flinders University (SBREC\#6408).

\section{$\underline{\text { Participants }}$}

The participants were 49 university students, primarily from China, commencing their undergraduate nursing degree out of a population of 320 commencing international nursing students. These participants were undertaking degrees of different course length, ranging from one to three years, and they varied in their previous nursing and educational experiences.

\section{Materials}

This study used official IELTS test results and three pen-and-paper items conducted in-house, which included a 100-item English C-test, a screening questionnaire, and a demographic questionnaire. The IELTS English scores (including subtest scores) were collected from official IELTS test report forms. The version of the C-test used in the study comprised five main paragraphs on the subjects of writing, teenagers, sleeping, health, and employment. The IELTS test was conducted independently by an external body, so the subject matter covered is unknown.

\section{Methods}

Posters were placed on pinboards around the nursing school and information sessions were held on site, which included the distribution of information sheets. Potential participants seeking to volunteer their time to the study were given a 1-minute screening questionnaire to confirm that they were international students commencing their nursing degree. Suitable applicants then undertook the 10-minute demographic questionnaire and were given 30 minutes to complete the C-test, which was held at the nursing school in the month they commenced their degree. They then undertook an independent IELTS test, requiring a whole day commitment, at an approved IELTS venue within four weeks (participants were reimbursed for the cost of the test when they submitted the results). Participants' topic grades were gathered from student records after one year of full-time study had passed, with the total data collection running between 2016-2017. Two weighted, aggregated, and averaged grade percentages were calculated for each participant, one for the classroom-based academic topics and one for the laboratory-based clinical topics. The results were analysed using IBM SPSS version 23 .

\section{Results}


The reliability and spread of the measures

The four parts of IELTS (speaking, writing, listening and reading) are meant to measure different aspects of language proficiency. A reliability analysis yielded a value of .803 for Cronbach's alpha and a factor analysis found only one factor underlying these four skills. This factor has an eigenvalue of 2.611 and explains $65.27 \%$ of the total variance. As no other factor with an eigenvalue above 1 emerges, and because of the high value for Cronbach's alpha, IELTS can be seen as unidimensional and does not measure the fours skills separately. To explain, a measure of the importance of a factor is the eigenvalue. It shows how much of the variance of all variables is accounted for by this factor; in other words, how important this factor is. An eigenvalue above 1 is necessary to include the factor in the model. The C-test is meant to be unidimensional and measure only one aspect: general language proficiency (the aspects of this general proficiency were discussed in the literature review). This is supported by our data as the five C-test sub-scores yielded a value for Cronbach's alpha of .885 , which makes it a reliable and robust test tool.

Table 1 Descriptive Statistics for the Predictor Variables

\begin{tabular}{|l|c|c|c|c|c|}
\hline Predictor & $\mathrm{N}$ & Minimum & Maximum & Mean & Std.Dev \\
\hline IELTS & 46 & 5.5 & 7.5 & 6.3 & .62 \\
\hline C-test & 49 & 37 & 96 & 71.6 & 13.68 \\
\hline
\end{tabular}

Table 2 Descriptive Statistics for the Dependent Variables

\begin{tabular}{|l|c|c|c|c|c|}
\hline Topic Type & $\mathrm{N}$ & Minimum & Maximum & Mean & Std.Dev \\
\hline Academic & 49 & 57 & 89.3 & 72.42 & 7.02 \\
\hline Clinical & 46 & 12 & 87.0 & 62.0 & 14.12 \\
\hline
\end{tabular}

The overall results for the predictor and dependent variables are shown in Table 1 and Table 2. The spread of the test scores were also analysed in order to identify the possibility of truncated samples. The two predictor variables are on different scales, so Figure 1 shows the spread of the standardized scores of the two variables.

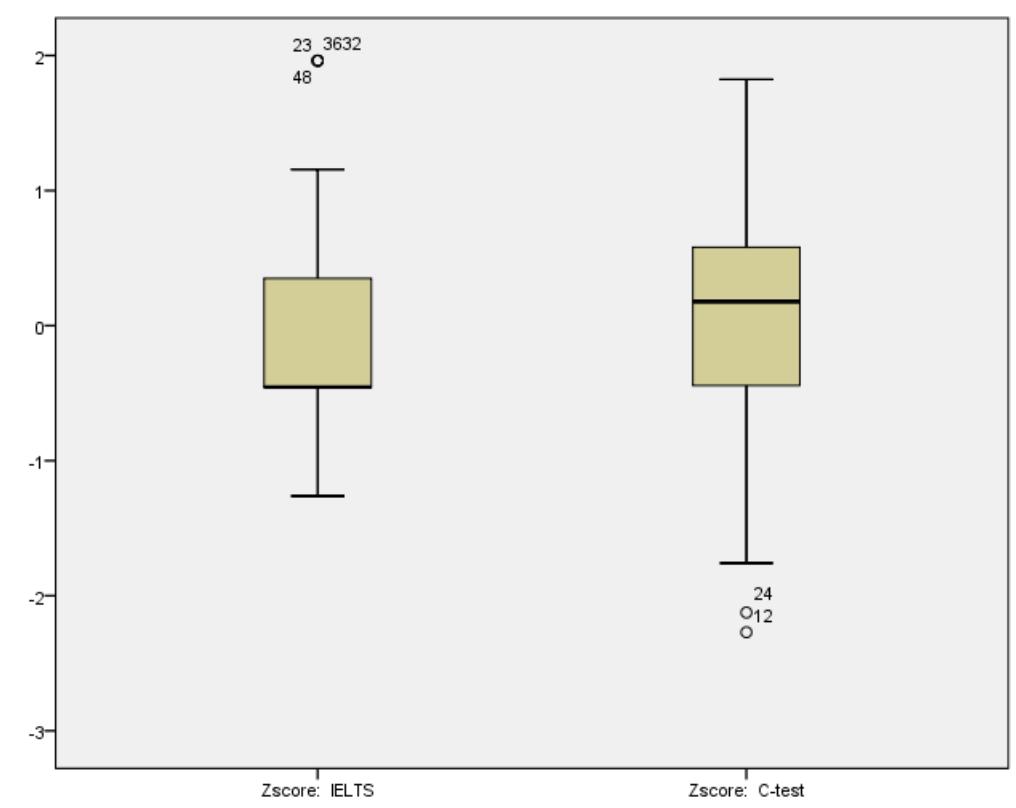

Figure 1. Spread of the scores for the predictor variables 
The largest relative spread is found in the C-test and the lowest in IELTS. This is in line with expectations, because IELTS scores have smaller variability for two main reasons. The first is due to the limited discrimination between possible scores between $0-9$, rising only in half-band increments (unlike the C-test which ranges between 0-100 in whole numbers), the nature of university enrolment where international students often aim to only achieve the minimum score of 6.5 required for university entry, and the issue of inflated IELTS scores due to students using welldrilled IELTS test-taking strategies. However, not many international students in our study entered through the English-testing pathway, so this study has the advantage of not having a truncated sample for IELTS scores: the main body of the scores stretches out from -1 to +1 standard deviations.

Regarding the relationship between the IELTS and the C-test, since they are both English language tests, the scores correlate significantly $(\mathrm{r}=.676, \mathrm{p}<.001, \mathrm{n}=46)$, which means a shared variance of $45.6 \%$. However, this also means that the two tests measure different aspects of English because $54.4 \%$ of the variance of each test cannot be explained by the other test. A further, more detailed, factor analysis based on all subscores of IELTS and the C-test confirms that the two tests measure different aspects of language proficiency, but that there is a common factor which explains $54.1 \%$ of the variance. This factor has an eigenvalue of 4.869 and has a positive loading on the four subtests of IELTS (listening, speaking, reading, and writing) and on the five subtests of the C-Test. There is, however, a second factor which explains an additional $12 \%$ of the variance with positive loadings for the IELTS subtests (apart from speaking) and negative loadings for two of the C-test subtests. This second factor shows that the tests seem to measure different aspects of language proficiency (see the "Discussion" section).

\section{The predictive validity of the tests}

The main question of our study was whether the two different types of test are related differently to the academic and clinical topics. We computed the correlation between the different predictor variables and the dependent variables. The results are shown in Table 3.

Table 3 Correlations (Pearson) between predictor variables and dependent variables

\begin{tabular}{|l|l|l|}
\hline Variables & Academic Topics & Clinical Topics \\
\hline IELTS & $.509 * * *$, & $.302^{*}$, \\
& $\mathrm{p}<.001, \mathrm{n}=46$ & $\mathrm{p}<.05, \mathrm{n}=43$ \\
\hline C-test & $.381^{* *}$, & $.417 * *$, \\
& $\mathrm{p}<.01, \mathrm{n}=49$ & $\mathrm{p}<.01, \mathrm{n}=46$ \\
\hline
\end{tabular}

* significant at the .05 level; ** significant at the .01 level; *** significant at the .001 level

Both the C-test and IELTS show significant correlations with both the academic and clinical topics, but these relationships varied. The highest correlation for academic topics was found for IELTS ( $r=$ $.509, \mathrm{p}<.001)$ and explained about $26 \%$ of the variance of academic topics, whereas the C-test, which was also significantly correlated $(r=.381, \mathrm{p}<.01)$, explained about $15 \%$ of the variance of the academic topics. The highest correlation for clinical topics was found for the C-test $(r=.417, \mathrm{p}$ $<.001$ ), explaining about $17 \%$ of variance of clinical topics, whereas IELTS, which was also significantly correlated $(r=.302, \mathrm{p}<.05)$, explained about $9 \%$ of the variance. The C-test was more highly correlated to clinical topics than IELTS, and vice versa for academic topics. 


\section{Discussion}

The research questions in this paper concerned the relationship between the IELTS and the C-test on performance in academic and clinical topics. The short answer is that both tests validly work in both arenas, but to differing degrees. The IELTS and C-test scores usually correlate with each other (see Daller \& Yixin, 2016) because they measure vocabulary knowledge that is relevant to the different language skills (see Eckes and Grotjahn 2006 for high correlations with a C-test in German to measures of listening, speaking, reading, and writing). This study's correlation and factor analysis also showed that the tests are correlated, but do not sit on a unidimensional scale. Since the C-test is also known to measure processing speed in the first language (Wockenfuß \& Raatz, 2014), this might be a more prominent aspect of completing the C-test over the IELTS test. Processing speed is a general psychological characteristic which goes beyond language processing, and one can assume that this also holds true for a second language. Similarly, the C-test is thought to evaluate a person's ability to restore missing elements - an 'expectancy grammar' - and IELTS may not test these features of language as intensively as the C-test.

Given that both tests were independently correlated to both types of topic, the efficacy of each test is worth exploring. If the reader recalls from the literature review, an average correlation for IELTS with grades is usually around .30 (or $9 \%$ of the variance). The C-test performed better than the IELTS average, with a significant positive correlation of .381 for academic topics, explaining $15 \%$ of the variance. This finding corresponds to that of a recent study by Daller and Yixin (2016). IELTS, on the hand, had an even higher correlation of 0.509 to academic topics in this study, reaching the highest correlation levels found in the literature (i.e. Hill, Storch, \& Lynch, 1999). One reason for this could be the robust amount of variance in ability found among the population and the effect this has on producing a more representative outcome. In Australia, while most international students are assumed to have undertaken an IELTS test to qualify for university entry, there are other very popular non-IELTS pathways. In this study, 31 participants entered university using the non-tested English College pathway. These participants were not required to pass the IELTS test and when officially tested at the start of this study (and the commencement of their degree), their actual IELTS scores ranged between 5.5-7.5. Of the ten trainee nurses who had the lowest IELTS score of 5.5, eight came through the English College pathway. These students added to the variation in IELTS scores because they put more weight on the lower scores than would be expected if the entry cut-off point of 6.5 was enforced for all students. This higher variation prevented the problem of a depressed predictive validity coefficient affecting the results, as alluded to in Daller \& Phelan (2013) and Huong (2001). Given the many factors that contribute to academic success, IELTS explaining $26 \%$ of variance in academic topics is remarkably good. If the ceiling effect on IELTS is true, then there were four students who scored IELTS 7.5 that may have negatively affected the correlation. The C-test itself performed at a level that is usually found for IELTS in other studies, and it is unknown if the C-test might have performed better if it focused on academic subject matter for its testing materials.

For clinical topics, IELTS maintained the typical .30 correlation that is found in the literature, albeit just scraping into significance at $\mathrm{p}=.049$ and explaining $9 \%$ of variance. The $\mathrm{C}$-test, as hypothesised, was correlated well to clinical topics, and at $.417(\mathrm{p}<.01)$, it explained $17 \%$ of the variance. This indicates that clinical topics may have linguistic or communicative elements that the C-test taps into better than IELTS. The manner in which fluency, processing speed, general 
vocabulary knowledge, and proficiency is tested by the C-test seems to match well with the construct of the language of healthcare outlined by Hull (2015).

An implication of this study is that nursing educators need to be aware that students entering through non-standardised pathways, such as an English language colleges (and others), may not actually have a level of English that would pass the rigour of an IELTS test. A surprising number of participants with extremely low IELTS scores entered through the English language college route, and those with IELTS below 6.0, when tested independently within this study, were the only ones who failed their topics. While these students may have developed some types of English language skills that will help them in the academic component of their studies, the international student cohort is by no means homogeneous and will certainly be of differing quality when it comes to English proficiency. Thus, even if English proficiency is apparently 'verified' before commencing a degree, there are different aspects of English required for each communicative context, either academic or clinical.

Further to this, a practical question could be raised about how academic support is provided by universities to its international students. There seems to be an assumption operating in universities that standard academic language activities are sufficient for nursing student success in their degrees. As a result, it is less common to find sustained healthcare-based specialised support for the students' professional communication needs (Müller, Arbon, \& Gregoric, 2015), although there are a number of shorter programmes which may be available (Crawford \& Candlin, 2013a; Crawford \& Candlin, 2013b). This study reinforces the need for support of the clinical language aspect of nursing, one which focuses on fluency and communication, especially given the level of distraction and multi-tasking that the clinical environment poses.

Another question can be posed about the use of academic English tests (e.g. IELTS and TOEFL) beyond the university setting, such as for measuring English proficiency for nursing registration. This is a common practice across all English-speaking countries, and probably stems from the important principle of using independent, standardised, impartially assessed, and secure tests, of which IELTS is one of a few available. However, tests such as IELTS are designed for academic purposes rather than for clinical settings, so they may not perform as well when assessing clinical communicative performance. At the very least, the C-test seems to perform better for this particular purpose. Thus, while the academic component of nursing is undeniably well-tested by IELTS in this study, other tests like the C-test or those which are made for clinical settings, such as the Occupational English Test (OET), should perhaps be reviewed for future registration requirements.

A final angle to consider is the cost of delivery and production. For a 49-person sample, the cost was approximately $\$ 150$ for the C-tests and $\$ 16,500$ for the IELTS tests. In terms of time, the C-test takes 30 minutes compared to the whole-day IELTS test. This equates to approximately AU\$3 per person taking half an hour to do the C-test with an immediate score, versus AU\$330 per person taking a whole day to do the IELTS test and a score which takes two weeks to return. Moreover, the C-test can be put online and marked electronically, for an even lower cost. A final advantage of the C-test is that it can be used as a method of quickly establishing the English proficiency of students entering through non-standardised pathways, or testing at-risk students to differentiate between language deficits and a lack of clinical knowledge. The $\mathrm{C}$-test can be administered and marked by the layperson, and can provide a reasonable snapshot of ability for the investment put into it. 
However, more work on benchmarking $\mathrm{C}$-test results against fails and grades certainly needs to be conducted to enable this to occur.

\section{Limitations}

The present study has some limitations due to the small sample size, but it also must be said that there was reasonable variation in ability among students and this would result in a reasonable approximation of the results likely to be found in a larger cohort. Larger follow-up studies are needed to corroborate results. Another potential limitation is the type of text used to create the Ctest. Four out of the five sub-texts were on general topics that do not test subject specific knowledge. This is in line with the classical C-test principle that suggests using 'neutral' texts (for details of C-test development see Klein-Braley 1985). However, there have been successful attempts to use C-tests with a focus on specific language aspects (Baghaei \& Grotjahn 2014; Daller \& Grotjahn, 1999). It would, therefore, be possible to create C-tests that are based on texts which have a nursing context. This could improve the predictive validity of the tests.

\section{Conclusion}

This study has found that both types of English test were significantly correlated to grades in both academic-focused and clinically-focused topics; however, they differed in their correlations. The IELTS test was best able to predict future grades in academic topics and $26 \%$ of variance in grades, while the C-test was able to predict $15 \%$ of variance in grades (which is the typical level of performance usually found for IELTS in other studies). However, when it came to clinical topics, the situation was reversed, with the C-test accounting for $17 \%$ of variance in clinical topic grades, and the IELTS test only accounting for $9 \%$ of clinical grade variance. Given the time and monetary cost of the IELTS test, it seems poor value for money (and time) in comparison to the C-test for clinical topics. For academic topics, the IELTS test was clearly a better predictor in this study, although the C-test seems to offer potential not only for quick on-the-spot testing, and a way of providing a common measure of non-IELTS entry pathways, but it also performed as well as an IELTS test, as expected according to the literature. Finally, the findings indicate that there may be different kinds of English needed for academic and clinical tasks, with the clinical tasks perhaps requiring better processing speed, for example. While there is a reasonable amount of overlap between the language used in academic and clinical settings, nurse educators and education institutions may better help international students by taking these different language demands into consideration when both testing and supporting the language skills of these students. 


\section{References}

Abu-Arab, A., \& Parry, A. (2015). Supervising culturally and linguistically diverse (CALD) nursing students: A challenge for clinical educators. Nurse Education in Practice, 15(4), e1-e9.

Ahern, S. (2009). "Like cars or breakfast cereal": IELTS and the trade in education and immigration. TESOL in Context, 19(1), 39-51.

Baghaei, P., \& Grotjahn, R. (2014). The validity of C-Tests as measures of academic and everyday language proficiency. In R. Grotjahn (Ed.) Der C-Test: Aktuelle Tendenzen/The C-Test: Current trends (pp.165-173). Frankfurt am Main: Lang.

Birrell, B. (2006). Implication of low English standards among overseas students at Australian universities. People and Place, 14(4), 53-64.

Blackman, I., \& Hall, M. (2009). Estimating the complexity of applied English language skills. In B. Matthews \& T. Gibbons (Eds.) The Process of Research in Education: A Festschrift in Honour of John P Keeves AM (pp.167-183). Adelaide, South Australia: Shannon Research Press.

Bosher, S. (2010). English for nursing: Developing discipline-specific materials. In N. Harwood (Ed.) English Language Teaching Materials: Theory and Practice (pp.346-372). Cambridge: Cambridge University Press.

Cambridge ESOL (2004). IELTS - Some frequently asked questions. Cambridge ESOL Research Notes, 18, 14-17.

Crawford, T., \& Candlin, S. (2013a). Investigating the language needs of culturally and linguistically diverse nursing students to assist their completion of the bachelor of nursing programme to become safe and effective practitioners. Nurse Education Today, 33, 796-801.

Crawford, T., \& Candlin, S. (2013b). A literature review of the language needs of nursing students who have English as a second/other language and the effectiveness of English language support programmes. Nurse Education in Practice, 13, 181-185.

Daller, H., \& Grotjahn, R. (1999). The language proficiency of Turkish returnees from Germany: An empirical investigation of academic and everyday language proficiency. Language, Culture and Curriculum, 12(2), 156-172.

Daller, M.H., \& Phelan, D. (2013). Predicting international student study success. Applied Linguistics Review, 4(1), 173-193.

Daller, M.H., \& Yixin, W. (2016). Predicting study success of international students. Applied Linguistics Review, online first publication.

Donnelly, T.T., McKiel, E., \& Hwang, J. (2009). Factors influencing the performance of English as an Additional Language nursing students: Instructors' perspectives. Nursing Inquiry 16(3), 201-211. Dooey, P. (1999). An investigation into the predictive validity of the IELTS Test as an indicator of future academic success. In K. Martin, N. Stanley, \& N. Davison (Eds.), Teaching in the Disciplines/Learning in Context, (pp.114-118). Proceedings of the 8th Annual Teaching Learning Forum, The University of Western Australia, February 1999, Perth: UWA, accessed 20 Aug 2010: http://lsn.curtin.edu.au/tlf/tlf1999/dooey.html. 
Eckes, T., \& Grotjahn, R. (2006). A closer look at the construct validity of C-tests. Language Testing, 23(3), 290-325.

Feast, V. (2002). The impact of IELTS scores on performance at university. International Education Journal, 3(4), 70-85.

Floyd, C.B. (2015). Closing the gap: International student pathways, academic performance and academic acculturation. Journal of Academic Language \& Learning, 9(2), A1-A118.

Grotjahn, R. (2016, Nov 16). The electronic C-test bibliography. Retrieved from http://www.Ctest.de.

Hill, K., Storch, N., \& Lynch, B. (1999). A comparison of IELTS and TEOFL as predictors of academic success. IELTS Research Reports, 2, 56-63.

Hull, M. (2015). Medical language proficiency: A discussion of interprofessional language competencies and potential for patient risk. International Journal of Nursing Studies, 54, 158-172.

Hopp, H. (2015). Semantics and morphosyntax in predictive L2 sentence processing. International Review of Applied Linguistics in Language Teaching, 53(3), 277-306.

Hopp, H. (2016). Learning (not) to predict: Grammatical gender processing in second language acquisition. Second Language Research, 32(2), 277-307.

Huong, T.T.T. (2001). The predictive validity of the International English Language Testing System (IELTS) test. Post-Script, 2(1), 66-96.

Ingram, D.E. (1995). An Australian perspective on the International English Language Testing System (IELTS). TESOL in Context, 5(2), 8-10.

Kerstjens, M., \& Nery, C. (2000). Predictive validity in the IELTS test: A study of the relationship between IELTS scores and students' subsequent academic performance. IELTS Research Reports, 3, 85-108.

Klein-Braley, C. (1985.) A cloze-up on the C-Test: A study in the construct validation of authentic tests. Language Testing, 2(1), 76-104.

Müller, A., Arbon, P., \& Gregoric, C. (2015). A school-based approach to developing the English proficiency of EAL university students. Journal of Academic Language \& Learning, 9(2), A63A78.

Oller, J.W. Jr. (1976). Evidence for a general language proficiency factor: An expectancy grammar. Die Neueren Sprachen, 75, 165-74.

Pardue, K.T., \& Haas, B. (2003). Curriculum considerations for enhancing baccalaureate learning for international students. The Journal of Continuing Education in Nursing, 34(2), 72-77.

Raatz, U. (1985). Tests of reduced redundancy - the C-Test, a practical example. In C. Klein-Braley \& U. Raatz (Eds.) Fremdsprachen und Hochschule 13/14: Thematischer Teil: C-Tests in der Praxis (pp.14-19). Bochum: AKS Verlag.

Raatz, U. \& Klein-Braley, C. (1985). How to develop a C-Test. Fremdsprachen und Hochschule, 13(14), 20-22.

Sigott, G. (2004). Towards identifying the C-Test construct. Frankfurt am Main: Lang. 
Sigott, G. (2006). How fluid is the C-Test construct? In R. Grotjahn (Ed.) Der C-Test: Theorie, Empirie, Anwendungen/The C-Test: Theory, Empirical Research, Applications (pp.139-146). Frankfurt am Main: Lang.

Spolsky, B. (1971). Reduced redundancy as a language testing tool. In G.E. Perren \& J.L.M. Trim (Eds.) Applications of Linguistics (pp.383-390). Cambridge: Cambridge University Press.

Starr, K. (2009). Nursing education challenges: Students with English as an additional language. Journal of Nursing Education, 48(9), 478-487.

Terwijn, R., Pearce, S., \& Rogers-Clark, C. (2012). A systematic review of the experiences of undergraduate nursing students choosing to study at an English speaking university outside their homeland. JBI Library of Systematic Reviews (JBI000476), 10(2), 66-186.

Wang, C.C., Andre, K., \& Greenwood, K.M. (2015). Chinese students studying at Australian universities with specific reference to nursing students: A narrative literature review. Nurse Education Today, 35(4), 609-19.

Wockenfuß, V., \& Raatz, U. (2014). Zur Validität von muttersprachli-chen C-Tests: Bedeutung von verbaler Intelligenz und Informationsverarbei-tungsgeschwindigkeit unter Berücksichtigung des Lebensalters. In R. Grotjahn (Ed.) Der C-Test: Aktuelle Tendenzen/The C-Test: Current trends (pp.191-224). Frankfurt am Main: Lang. 